\title{
THE VIRTUAL MANUFACTURING CONCEPT: SCOPE, SOCIO-ECONOMIC ASPECTS AND FUTURE TRENDS.
}

\author{
P. Dépincé, D. Chablat \\ Institut de Recherche en Communications \\ et Cybernétique de Nantes * \\ 1, rue de la Noë, 44321 Nantes, France \\ Philippe.Depince@irccyn.ec-nantes.fr
}

\author{
E. Noël \\ CECIMO \\ 66 avenue Louise, \\ 1050 Brussels, Belgium \\ eco-dep@cecimo.be
}

\author{
P.O. Woelk \\ Institute of Production Engineering \\ and Machine Tools (IFW) \\ Schlosswender Strasse 5, \\ D-30159 Hannover, Germany \\ Woelk@ifw.uni-hannover.de
}

\section{ABSTRACT}

The research area "Virtual Manufacturing (VM)" is the use f information technology and computer simulation to model eal world manufacturing processes for the purpose of analysing and understanding them. As automation technologies such as CAD/CAM have substantially shortened the time required to deIsign products, Virtual Manufacturing will have a similar effect on the manufacturing phase thanks to the modelling, simulation and optimisation of the product and the processes involved in its Tabrication. After a description of Virtual Manufacturing (defiAitions and scope), we present some socio-economic factors of (1) VM and finaly some "hot topics" for the future are proposed.

\section{ANNTRODUCTION}

Manufacturing is an indispensable part of the economy and the central activity that encompasses product, process, reSources and plant. Nowadays products are more and more complex, processes are highly-sophisticated and use microtechnology and mechatronic, the market demand (lot sizes) evolves rapidly so that we need a flexible and agile production. Moreover manufacturing enterprises may be widely distributed geographically and linked conceptually in terms of dependencies and material, information and knowledge flows. In this complex and evolutive environment, industrialists must know about

*IRCCyN: UMR n 6597 CNRS, École Centrale de Nantes, Université de Nantes, École des Mines de Nantes their processes before trying them in order to get it right the first time. To achieve this goal, the use of a virtual manufacturing environment will provide a computer-based environment to simulate individual manufacturing processes and the total manufacturing enterprise. Virtual Manufacturing systems enable early optimization of cost, quality and time drivers, achieve integrated product, process and resource design and finally achieve early consideration of producibility and affordability. The aim of this paper is to present an updated vision of Virtual Manufacturing (VM) through different aspects. This vision is the result of a survey done within the thematic European Network MANTYS. As, since 10 years, several projects and workshops have dealt with the Virtual Manufacturing thematic, we will first define the objectives and the scope of VM and the domains that are concerned. The expected technological benefits of VM will also been presented. In a second part, we will present the socio-economic aspects of VM. This study will take into account the market penetration of several tools with respect to their maturity, the difference in term of effort and level of detail between industrial tools and academic research. Finally the expected economic benefits of VM will be presented and a focus will be made on SMEs. The last part will describe the trends and exploitable results in machine tool industry (research and development towards the "Virtual Machine Tool"), automotive (Digital Product Creation Process to design the product and the manufacturing process) and aerospace. A brief description of "hot topics" is proposed. 


\section{MANTYS: THEMATIC NETWORK ON MANUFACTUR- ING TECHNOLOGIES}

The MANTYS Thematic Network is supported by the European Commission Growth Programme (FP5) and promotes innovation in the field of manufacturing technologies, focusing on machinery. It provides a European platform that enables research and industrial participants to exchange views and research results in technology, socio-economic issues, sustainability and the quality of life in all aspects of manufacturing. It was launched in September 2001 and brings together:

-over 20 European RTD laboratories and research institutes with eminent reputations in manufacturing technologies,

-a socio-economic task force composed of various experts from universities, private companies and machine tool builders' associations,

-an Industrial Advisory Committee representing the automotive, aerospace, mechanical and machine building sectors.

The MANTYS Thematic Network has established a framework in which researchers and industrialists communicate and reach common view of technological progress and its opportunities. Potential synergies between different projects are made apparent and co-operation promoted, to enhance the creation of the European Research Area in manufacturing technologies. MANTYS was actually proved to be a very efficient communication platform at the launch of the 6th Framework Programme, by allowing researchers and EC officials to meet one another and discuss proposals for FP6 projects.

Furthermore, the MANTYS Thematic Network promotes the widest exploitation of research results across sectors. Results from over 80 research projects have been so far assessed and used to create Technology Trend Reports on 5 key technological areas: Reliability, Process monitoring - Control; Agility Flexibility; Process ECO-Efficiency; Precision Engineering and Virtual Manufacturing.

MANTYS is generating insight into the mechanisms that relate technological innovation to socio-economic factors. Building on this, it will identify realistic scenarios based on likely technological and socio-economical developments. These will be used to assess strategic impact. Also, "Technology Road Maps" will be produced, preparing decision makers to orient their activities and to adapt to change.

\section{Virtual Manufacturing technology area}

Virtual Manufactturing has always been supported by the European commission during all the framework programs. During the FP3, the CIM-OSA association has been creating and it is stil active. This European organization is attempting to develop Open System Architecture (OSA) standards for CIM (Computer Integrated Manufacturing) environments. CIMOSA [ 4 ] provides a process oriented modelling concept that captures both the pro- cess functionality and the process behaviour. It supports evolutionary enterprise modelling, e.g., the modelling of individual enterprise domains (DM) which may contain one or several individual processes (P-1, P-2, ...) (Fig. 11).

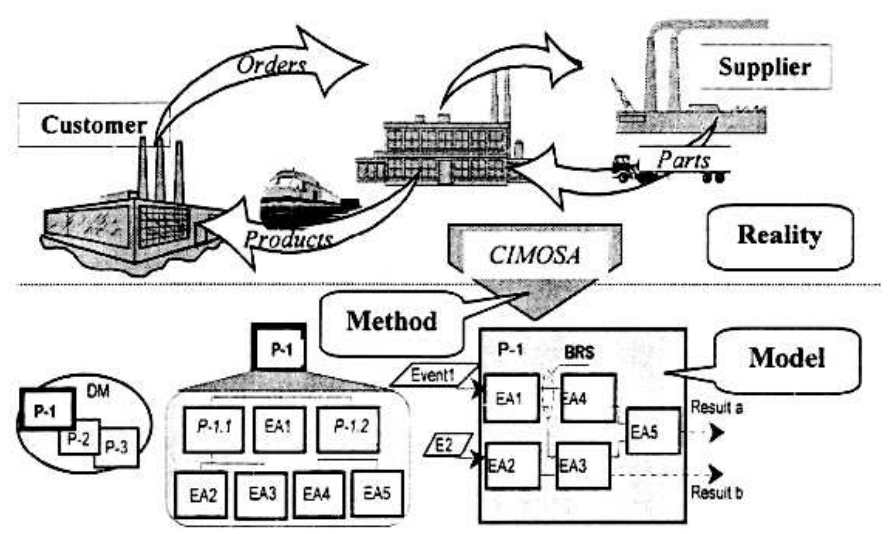

Figure 1. ENTERPRISE MODELING - CIMOSA MODEL

The aims of MANTYS in the field of Virtual Manufacturing are to promote the successful exploitation of innovative technologies across sectors, establish a continuously updated view on technological trends and identify strategies and scenarios for future technological Research and Development. The tools used to achieve this objectives are : the establishment of innovation sheets on different European or national project dealing with Virtual Manufacturing - some examples are given in Table 1 -, the establishment of trend reports and public information dissemination.

\section{WHAT IS VIRTUAL MANUFACTURING? Virtual manufacturing definitions}

The term Virtual Manufacturing is now widespread in literature but several definitions are attached to these words. First we have to define the objects that are studied. Virtual manufacturing concepts originate from machining operations and evolve in this manufacturing area. However one can now find a lot of applications in different fields such as casting, forging, sheet metalworking and robotics (mechanisms). The general idea one can find behind most definitions is that "Virtual Manufacturing is nothing but manufacturing in the computer". This short definition comprises two important notions: the process (manufacturing) and the environment (computer). In [1, 2] VM is defined as “...manufacture of virtual products defined as an aggregation of computerbased information that... provide a representation of the properties and behaviors of an actualized product". Some researchers present VM with respect to virtual reality (VR). On one hand, 


\begin{tabular}{|l|l|}
\hline Acronym & Short description \\
\hline Fashion & $\begin{array}{l}\text { Fully integrated simulation and optimization for en- } \\
\text { hancing advanced machine tools design }\end{array}$ \\
\hline MECOMAT & Mechatronic compiler for machine tool design \\
\hline MICROHARP & $\begin{array}{l}\text { Development of hard turning towards a micron ac- } \\
\text { curacy capability process for serial production }\end{array}$ \\
\hline ProREAL & $\begin{array}{l}\text { Virtual reality based methods and tools for appli- } \\
\text { cations related with planning and training tasks in } \\
\text { manufacturing processes }\end{array}$ \\
\hline RRS & Realistic Robot Simulation \\
\hline SAM & New structural alternative for modules in machinery \\
\hline SPI-9 & $\begin{array}{l}\text { Design System for simultaneous engineering ap- } \\
\text { plied to production systems }\end{array}$ \\
\hline VIR-ENG & $\begin{array}{l}\text { Integrated design, simulation and distributed con- } \\
\text { trol of agile modular manufacturing machinery }\end{array}$ \\
\hline$\ldots$ & $\ldots$ \\
\hline
\end{tabular}

Table 1. EC FP5 projects linked to VM

in [3] VM is represented as a virtual world for manufacturing, on the other hand, one can consider virtual reality as a tool which offers visualization capabilities for VM [5,6]. The most comprehensive definition has been proposed by the Institute for Systems Research, University of Maryland, and discussed in [7, 8]. Virtual Manufacturing is defined as "an integrated, synthetic manufacturing environment exercised to enhance all levels of decision and control" (Fig. 2).

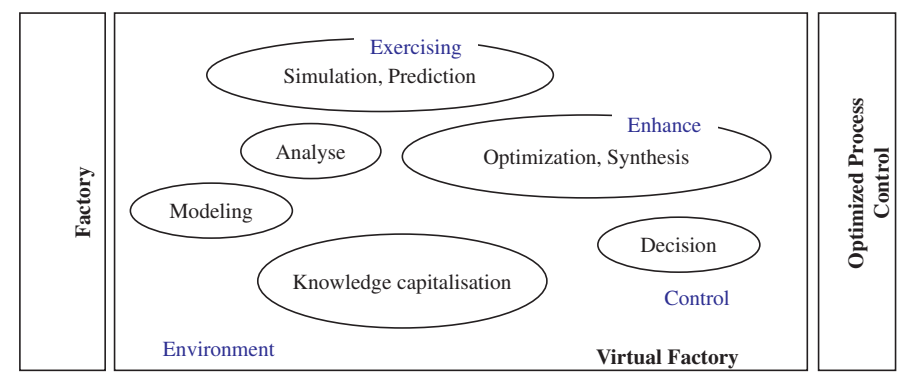

Figure 2. VIRTUAL MANUFACTURING

Environment: supports the construction, provides tools, models, equipment, methodologies and organizational principles,

Exercising: constructing and executing specific manufacturing simulations using the environment which can be composed of real and simulated objects, activities and processes,
Enhance: increase the value, accuracy, validity,

Levels: from product concept to disposal, from factory equipment to the enterprise and beyond, from material transformation to knowledge transformation,

Decision: understand the impact of change (visualize, organize, identify alternatives).

A similar definition has been proposed in [8]: "Virtual Manufacturing is a system, in which the abstract prototypes of manufacturing objects, processes, activities, and principles evolve in a computer-based environment to enhance one or more attributes of the manufacturing process."

One can also define VM focusing on available methods and tools that allow a continuous, experimental depiction of production processes and equipment using digital models. Areas that are concerned are (i) product and process design, (ii) process and production planning, (iii) machine tools, robots and manufacturing system and virtual reality applications in manufacturing.

\section{The scope of Virtual Manufacturing}

The scope of VM can be to define the product, processes and resources within cost, weight, investment, timing and quality constraints in the context of the plant in a collaborative environment. Three paradigms are proposed in [栉:

-Design-centered VM: provides manufacturing information to the designer during the design phase. In this case VM is the use of manufacturing-based simulations to optimize the design of product and processes for a specific manufacturing goal (DFA, quality, flexibility, ...) or the use of simulations of processes to evaluate many production scenario at many levels of fidelity and scope to inform design and production decisions.

-Production-centered VM: uses the simulation capability to modelize manufacturing processes with the purpose of allowing inexpensive, fast evaluation of many processing alternatives. From this point of view VM is the production based converse of Integrated Product Process Development (IPPD) which optimizes manufacturing processes and adds analytical production simulation to other integration and analysis technologies to allow high confidence validation of new processes and paradigms.

-Control-centered VM: is the addition of simulations to control models and actual processes allowing for seamless simulation for optimization during the actual production cycle.

Another vision is proposed by Marinov in [9, 10]. The activities in manufacturing include design, material selection, planning, production, quality assurance, management, marketing, .... If the scope takes into account all these activities, we can consider this system as a Virtual Production System. A VM System includes only the part of the activities which leads to a change 
of the product attributes (geometrical or physical characteristics, mechanical properties, ...) and/or processes attributes (quality, cost, agility, ...). Then, the scope is viewed in two directions: a horizontal scope along the manufacturing cycle, which involves two phases, design and production phases, and a vertical scope across the enterprise hierarchy. Within the manufacturing cycle, the design includes the part and process design and, the production phase includes part production and assembly.

We choose to define the objectives, scope and the domains concerned by the Virtual Manufacturing thanks to the 3D matrix represented in Fig. 3 .

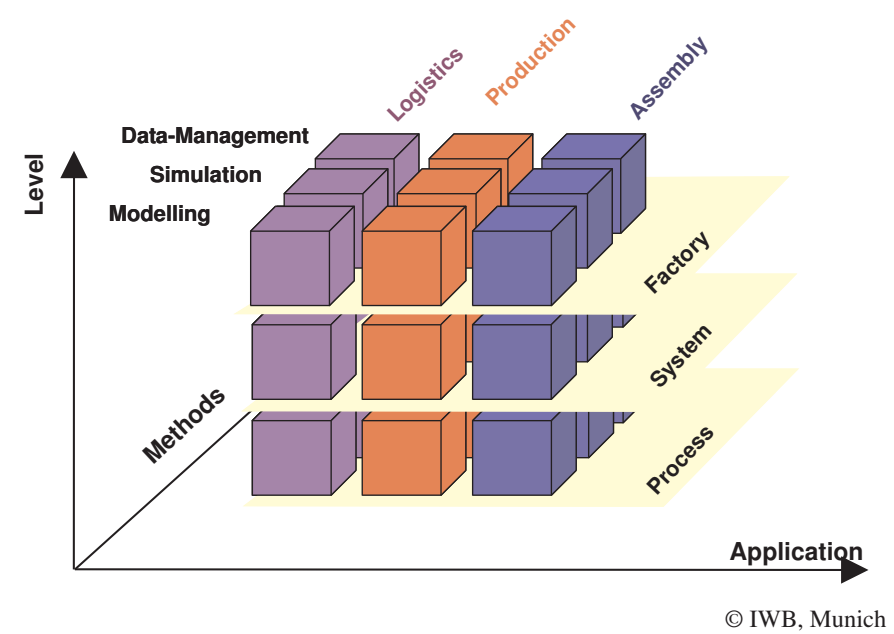

Figure 3. VIRTUAL MANUFACTURING OBJECTIVES, SCOPES AND DOMAINS

The vertical plans represent the three main aspects of manufacturing today: Logistics, Productions and Assembly, which cover all aspects directly related to the manufacturing of industrial goods. The horizontal planes represent the different levels within the factory. At the lowest level (microscopic level), VM has to deal with unit operations, which include the behavior and properties of material, the models of machine tool - cutting tool workpiece - fixture system. These models are then encapsulated to become VM cells inheriting the characteristics of the lower level plus some extra characteristics from new objects such as a virtual robot. Finally, the macroscopic level (factory level) is derived from all relevant sub-systems. The last axis deals with the methods we can use to achieve VM systems. These methods will be discussed in the next paragraph.

\section{Methods and tools used in Virtual manufacturing}

Two main activities are at the core of VM. The first one is the "modeling activity" which includes determining what to model and the degree of abstraction that is needed. The second one is the ability to represent the model in a computer-based environment and to correlate to the response of the real system with a certain degree of accuracy and precision: the "simulation activity". Even if simulation tools often appears to be the core activity in VM, others research areas are relevant and necessary. One can find in a classification of the technologies within the context of VM in 4 categories:

A "Core" technology is a technology which is fundamental and critical to VM. The set of "Core" technologies represents what VM can do.

An "Enabling" technology is necessary to build a VM system.

A "Show stopper" technology is one without which a VM system cannot be built.

"Common" technology is one that is widely used and is important to VM.

We propose the following activities to underline methods that are necessary to achieve a VM system:

-Manufacturing characterization: capture, measure and analyze the variables that influence material transformation during manufacturing (representation of product/process, design by features, system behavior, ...),

-Modeling and representation technologies: provide different kinds of models for representation, abstraction, standardization, multi-use, ... All the technologies required to represent all the types of information associated with the design and fabrication of the products and the processes in such a way that the information can be shared between all software applications (Knowledge based systems, Object oriented, feature based models, ...)

-Visualization, environment construction technologies: representation of information to the user in a way that is meaningful and easily comprehensible. It includes Virtual reality technologies, graphical user interfaces, multi context analysis and presentation.

-Verification, validation and measurement: all the tools and methodologies needed to support the verification and validation of a virtual manufacturing system (metrics, decision tools, ...).

-Multi discipline optimization: VM and simulation are usually no self-standing research disciplines, they often are used in combination with "traditional" manufacturing research.

Numerous tools are nowadays available for simulating the different levels described in Fig. 3: from the flow simulation thanks to discrete event simulation software to finite elements analysis. The results of these simulations enable companies to optimise key factors which directly affects the profitability of their manufactured products. Table 2 proposes an overview of simulation applications in manufacturing.

-Flow simulation - discrete event simulation software: It is composed of object-oriented discrete event simulation tool to ef- 


\begin{tabular}{|l|l|l|l|}
\hline $\begin{array}{l}\text { Manufacturing } \\
\text { Level }\end{array}$ & Type of simulation & Simulation targets & $\begin{array}{l}\text { Level of } \\
\text { detail }\end{array}$ \\
\hline $\begin{array}{l}\text { Factory / } \\
\text { shop floor }\end{array}$ & $\begin{array}{l}\text {-Flow simulation } \\
\text {-Business process } \\
\text { simulation }\end{array}$ & $\begin{array}{l}\text {-Logistic and storage } \\
\text {-Production principles } \\
\text {-Production planning } \\
\text { and control }\end{array}$ & low \\
\hline $\begin{array}{l}\text { Manufacturing } \\
\text { systems / } \\
\text { manufacturing } \\
\text { lines }\end{array}$ & -Flow simulation & $\begin{array}{l}\text {-System layout } \\
\text {-Material flow } \\
\text {-Control strategies } \\
\text {-System capacity } \\
\text {-Personnel planning }\end{array}$ & Intermediate \\
\hline $\begin{array}{l}\text { Manufacturing } \\
\text { cell / } \\
\text { Machine tool } \\
\text { / robot }\end{array}$ & $\begin{array}{l}\text {-Flow simulation } \\
\text {-Graphical 3D } \\
\text { tion }\end{array}$ & $\begin{array}{l}\text {-Cell layout } \\
\text {-Programming } \\
\text {-Collision test }\end{array}$ & High \\
\hline Components & $\begin{array}{l}\text {-Finite-Elements } \\
\text {-Multibody simula- } \\
\text { tion } \\
\text {-Bloc simulation }\end{array}$ & $\begin{array}{l}\text {-Structure (mechani- } \\
\text { cal and thermal) } \\
\text {-Electronic circuits } \\
\text {-Non-linear move- } \\
\text { ment dynamics }\end{array}$ & Complex \\
\hline $\begin{array}{l}\text { Manufacturing } \\
\text { processes }\end{array}$ & -Finite-Elements \\
analysis & $\begin{array}{l}\text {-Cutting processes: } \\
\text { surface properties, } \\
\text { thermal effects, tool } \\
\text { wear / life time, chip } \\
\text { creation } \\
\text {-Metal forming pro- } \\
\text { cesses: formfill, mate- } \\
\text { rial flow (sheet metal), } \\
\text { stresses, cracks }\end{array}$ & Very \\
complex \\
\hline
\end{tabular}

Table 2. SIMULATIONS TOOLS

ficiently model, experiment and analyze facility layout and process flow. It aids at the determination of optimal layout, throughput, cost and process flow for existing or new systems. It simulates and optimizes production lines in order to accommodate different order sizes and product mixes.

-Graphical 3D - Kinematics simulation: There are used in robotic and machine tools simulation tools for design, evaluation, and off-line programming of workcells. They can incorporate real world robotic and peripheral equipment, motion attributes, kinematics, dynamics and I/O logic.

-Finite elements analysis: A powerfull engineering design tool that has enabled companies to simulate all kind of fabrication and testing in a more realistic manner. It can be use in combination with optimisation tool as a tool for decision making. It allows to reduce the number of prototypes as virtual prototype are cheaper than building physical models, the material waste and the cost of tooling,...

\section{ECONOMICS AND SOCIO-ECONOMICS FACTOR OF VIRTUAL MANUFACTURING \\ Expected benefits}

As small modifications in manufacturing can have important effects in terms of cost and quality, Virtual Manufacturing will provide manufacturers with the confidence of knowing that they can deliver quality products to market on time and within the initial budget. The expected benefits of VM are:

-from the product point of view it will reduce time-tomarket, reduce the number of physical prototype models, improve quality, ...: in the design phase, VM adds manufacturing information in order to allow simulation of many manufacturing alternatives: one can optimize the design of product and processes for a specific goal (assembly, lean operations, ...) or evaluate many production scenarios at different levels of fidelity,

-from the production point of view it will reduce material waste, reduce cost of tooling, improve the confidence in the process, lower manufacturing cost,...: in the production phase, VM optimizes manufacturing processes including the physics level and can add analytical production simulation to other integration and analysis technologies to allow high confidence validation of new processes or paradigms. In terms of control, VM can simulate the behavior of the machine tool including the tool and part interaction (geometric and physical analysis), the NC controller (motion analysis, look-ahead).

VM and simulation change the procedure of product and process development. Prototyping will change to virtual prototyping so that the first real prototype will be nearly ready for production. This is intended to reduce time and cost for any industrial product. Virtual manufacturing will contribute to the following benefits [0]:

1 Quality: Design For Manufacturing and higher quality of the tools and work instructions available to support production;

2 Shorter cycle time: increase the ability to go directly into production without false starts;

3 Producibility: Optimise the design of the manufacturing system in coordination with the product design; first article production that is trouble-free, high quality, involves no reworks and meets requirements.

4 Flexibility: Execute product changeovers rapidly, mix production of different products, return to producing previously shelved products;

5 Responsiveness: respond to customer "what-ifs" about the impact of various funding profiles and delivery schedule with improved accuracy and timeless,

6 Customer relations: improved relations through the increased participation of the customer in the Integrated Product Process Development process. 


\section{Economic aspects}

It is important to understand the difference between academic research and industrial tools in term of economic aspects. The shape of the face in the diagram presented in Fig. (4 [11], is defined by two curves:

-"effort against level of detail" where "level of detail" refers to the accuracy of the model of simulation (the number of elements in the mesh of a FEM model or the fact if only static forces are taken into account for a simulation,

-"effort against development in time" is a type of time axis and refers to future progress and technological developments (e.g. more powerful computers or improved VR equipment).

Universities develop new technologies focusing on technology itself. Researchers do not care how long the simulation will need to calculate the results and they not only develop the simulation but they need to develop the tools and methods to evaluate whether the simulation is working fine and whether the results are exact. On the other hand, industrial users focus on reliability of the technology, maturity economic aspects (referring to the effort axis) and on the integration of these techniques within existing information technology systems of the companies (e.g. existing CAD-CAM systems, ...). To our mind, Virtual Manufacturing is, for a part of its scope, still an academic topic. But in the future, it will become easier to use these technologies and it will move in the area of industrial application and then investments will pay off. For example in the automotive and aerospace companies in the late 60's, CAD was struggling for acceptance. Now 3-D geometry is the basis of the design process. It took 35 years for CAD-CAM to evolve from a novel approach used by pioneers to an established way of doing things. During this period, hardware, software, operating systems have evolved as well as education and organizations within the enterprise in order to support these new tools. Fig. 5 presents a classification of VM applications with respect to market penetration and maturity. Three classes can be determined: some techniques are daily used in industry, some are mature but their uses are not widespread and some are still under development.

No doubt that the current developments in virtual manufacturing and the growing interest of the industries for this area are influenced by the changes that have recently taken place in our society. The old industrial model, which was characterized by "real" activities, work and capital, is over. Focusing on manufacturing technology domain, four stages in its evolution can be identified [12]:

-Craftsman (pre-1870): Highly flexible system with economy of scope and quality. Mostly artisans who started from the design until the delivery,

-mass production (1870-1945): Standardization, interchangeability of parts. Mechanization of the manufacturing process. Economy of scale justified the high cost of the production machines,

-automation technology (1945-1995): Automation served to

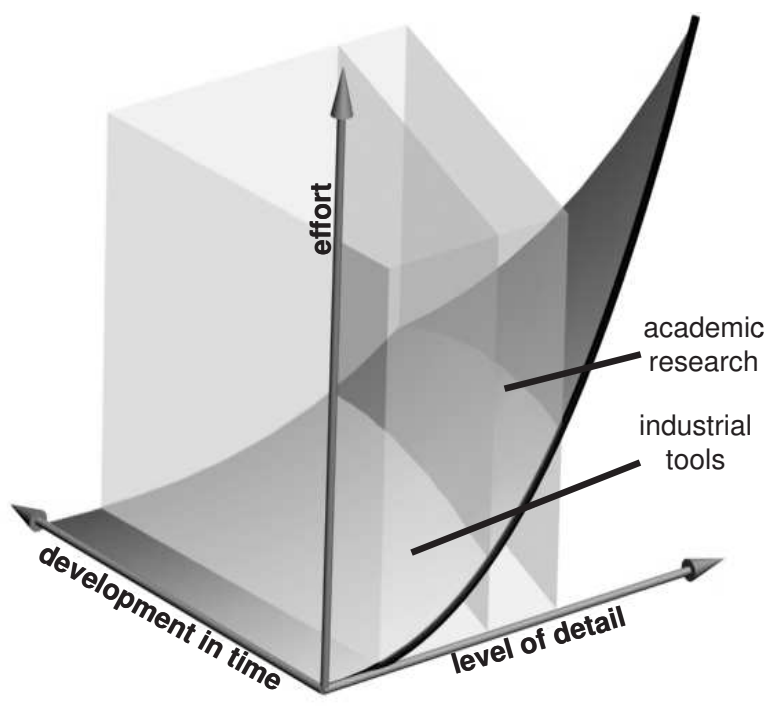

Figure 4. ACADEMIC RESEARCH VERSUS INDUSTRIAL TOOLS

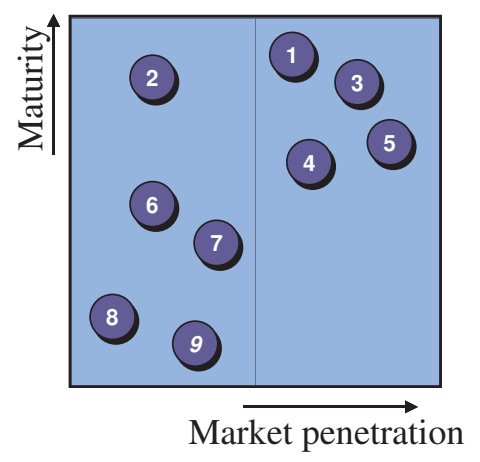

1) Multibody simulation in car development (eg. chassis design) Multibody simulation in machine tool development

FEM in optimisation of machine tool structures

Simulation of flow of material/ logistics

(5) (based on geometry)

CAM simulation

6 (based on technology)

Simulation of flow in combustion engine development

8. Virtual machine tool,

FEM in simulation of cutting forces

(IFW

Figure 5. MATURITY OF TECHNIQUES VERSUS MARKET PENETRATION

bridge the gap between the highly flexible craftsman and the highly volume dependent mass production,

-IT-based manufacturing network (1995-present): CNCs, robots, FMS, ... often linked via local area networks. The emergence of IT and Internet enables the development of new distributed networks.

Today, the work has been redistributed. Shareholders run companies and evaluate activities globally. In this new frame, Virtual Manufacturing will allow companies to maximise the shareholder value by enabling companies that operate in a global market to take advantage of the globalisation of exchanges and economic activities. It will be easier to transfer mass production to a specific country corresponding to certain criteria, while 
others are developing the ideas. IT will reduce organizational and geographical barriers to collaboration and can replace physical movement (of people, materials, ...) with digital movement. However question dealing with the balancing of these new activities remains open and leads to various ethical questions.

One of the major advantages of Virtual Manufacturing for large companies is the possibility to set up virtual organisations. With such a tool, companies can now concentrate on core business and outsource all secondary activities. The main reason for companies to transfer and outsource activities is that it increases the cost efficiency and release resources for more essential projects. The development of the know-how and interfaces as well as security aspects of a Virtual Manufacturing system should not be underestimated and remain critical in the decision process to invest or not in Virtual Manufacturing.

\section{SMEs and Virtual Manufacturing}

As presented earlier, VM appeared to be a set of IT technologies which are now mature and whose benefits for industry are numerous. If large manufacturing enterprises (LMEs) have developed and applied with success these technologies (automotive, aerospace, ...) it is not the case for the majority of SMEs. Publications dealing with VM are mainly about new capabilities or products or describe succes stories how they have been implemented in LMEs.

First of all, VM is a capital intensive technology and a lot of SMEs do not have the wherewithal to integrate them. VM technologies are still quite expensive to own. There are clear differences between SMEs and LMEs [12]: the both of them need growth and operate in a highly competitive market. However, SMEs lack the basis competitive infrastructure such as cash flow, trained employees, ... They are resource poor and they do not have time and money to speculate on IT.

As pointed out by recent reports, SMEs are the "base" of most manufacturing economies and as manufacturing "creates the real wealth" in any economy, SMEs can be seen as the backbone of these economies. Due to this economic importance, it seems important to have positive and sustained policies for the growth of the SMEs. In European Union, the commission emphasizes the participation of SMEs in the FP6 program but it appears that a lot of time have to be spent to convince them of the usefulness of their participation and what are the potential benefits they can have. Moreover they do not have the means and the "research culture" to be the leader of such a project.

Nowadays we have to find means to face the dilemma of SMEs and VM: if no ways of dissemination of VM technologies to the SMEs are found, they will continue to be a mirage. The need for a quick and appropriate answer is increased by the development of the Virtual Enterprise [14, 13]. Some propositions, as Telemanufacturing (e-manufacturing), have appeared [12]: "Telemanufacturing is an infrastructure whereby a firm uti- lizes services afforded via communications networks and across information superhighways to perform for the design and production of items".

\section{TRENDS AND EXPLOITABLE RESULTS Machine-tool}

The trend in the machine tool manufacturers sector concerning Virtual Manufacturing is research and development towards the "Virtual Machine Tool". One of the goals of the Virtual Machine Tool is to reduce time and cost for the developing of new machine tools by introducing virtual prototypes that are characterized by a comprehensive digital geometrical design, and by the simulation of (1) the stationary behavior of the machine structure, (2) the dynamic behavior of moving parts, (3) the changing of signals and state variables in electronic circuits and (4) by the simulation of the manufacturing process itself. A second goal is the simulation of machining processes taking into account the behavior of the mechanical structure (stresses, deformation, eigenfrequencies of the moving parts, determination of temperature distribution, contact behaviour between tool and part, the determination of cutting forces, vibrations, chatter, ...) and the mechatronic drives, moving system and the controler.

Nowadays, the simulation activities are isolated from each other. Current research is combining different types of simulation to reflect various interdependencies, like e.g. elaborating the frequency response with FEA and combining this with a bloc simulation of the machine. The process simulation of forming processes is almost state-of-the-art in industry, whereas the simulation of cutting processes is an item for international research (this excludes the pure NC-program simulation, which is widely used in industry, but which does not reflect the realistic behavior of the interaction of machine tool, tool and work piece during cutting operations).

\section{Automotive}

In the automotive industry, the objective of the Digital Product Creation Process is to design the product and the manufacturing process digitally with full visualization and simulation for the three domains: product, process and resources. In this case a broad view of manufacturing is adopted and the so-called "big M" manufacturing encompasses not only fabrication, assembly and logistics processes but all functions associated with the entire product realization process: from the understanding of customers' needs to delivery and customer services. A not so futuristic scenario dealing with automobile can be found in [15].

The product domain covers the design of individual part of the vehicle (including all the data throughout the product life cycle), the process domain covers the detailed planning of the manufacturing process (from the assignment of resources and optimization of workflow to process simulation). Flow simulation of 
factories and ware houses, 3D-kinematics simulation of manufacturing systems and robots, simulation of assembly processes with models of human operators, and FEA of parts of the automobiles are state-of-the-art (Fig. 6).

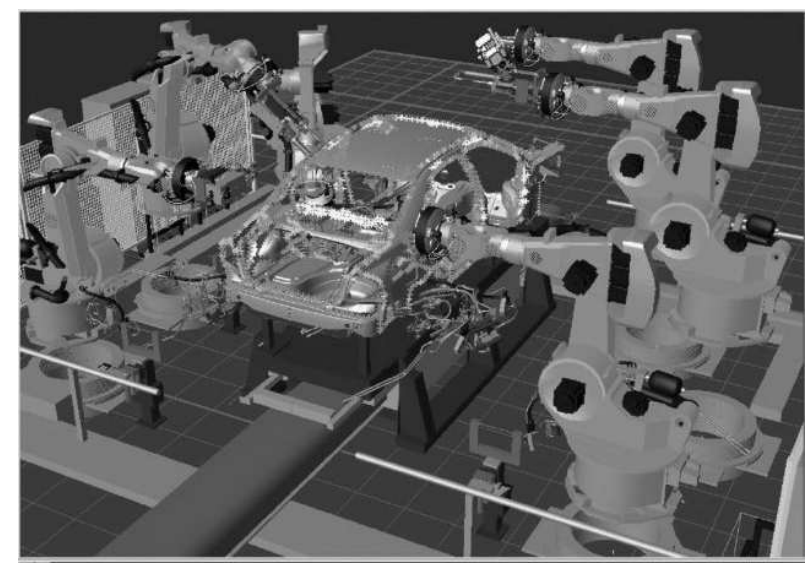

Figure 6. SIMULATION OF A ROBOTIC CELL WITH eM-Workplace (TECNOMATIX)

New trends are focusing on the application of Virtual and Augmented Reality technologies. Virtual Reality technologies, like e.g. stereoscopic visualization via CAVE and Powerwall, are standard in product design. New developments adapt these technologies to manufacturing issues, like painting with robots. Developments in Augmented Reality focus on co-operative telework, where developers located in distributed sites manipulate a virtual work piece, which is visualized by Head Mounted Displays.

\section{Aerospace}

Virtual Manufacturing in aerospace industry is used in FEA to design and optimise parts, e.g. reduce the weight of frames by integral construction, in 3D-kinematics simulation to program automatic riveting machines and some works dealing with augmented reality to support complex assembly and service tasks (the worker sees needed information within his glasses).

The simulation of human tasks with mannequins allows the definition of useful virtual environnement for assembly, maintenance and training activities [16]. The access and visibility task taking into account ergonomic constraints are defined to check the ability of mannequin in virtual environments, as depicted in Fig. 8.

\section{Drawbacks - Hot topics}

As shown before, a lot of tools and technologies are available in the field of Virtual Manufacturing and even if gains they

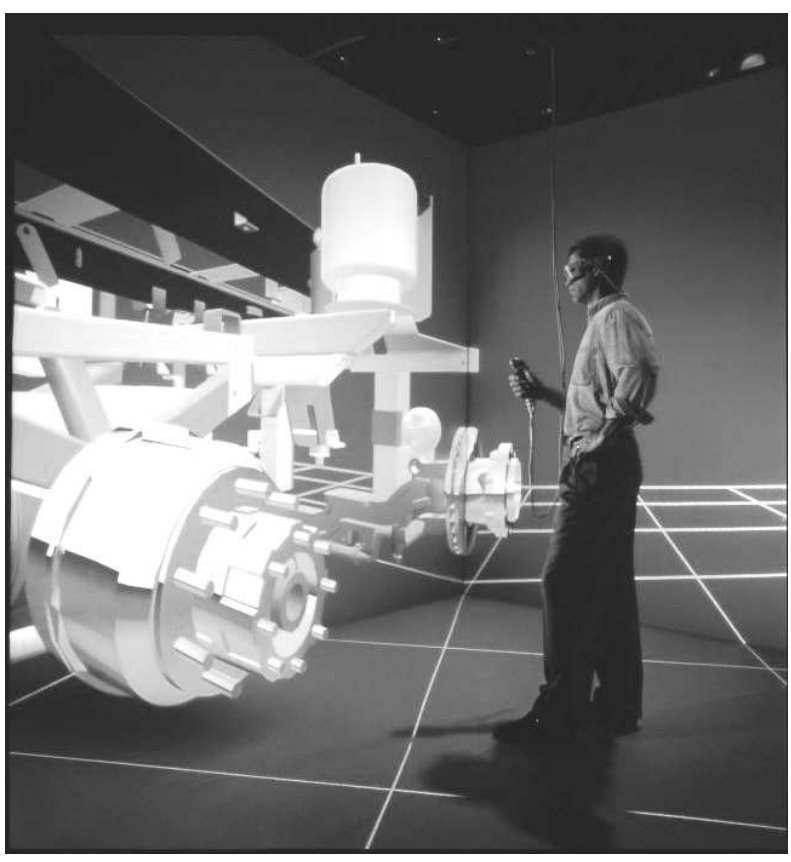

Figure 7. PROJECT REVIEW USING A CAVE (SGI)

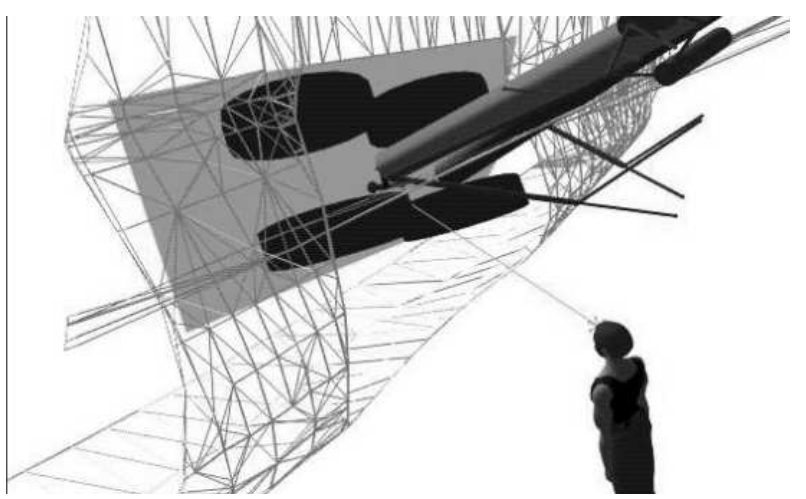

Figure 8. CHECK THE VISUAL ACCESSIBILITY UNDER A TRAP OF AN AIRCRAFT

can offer are well documented in LMEs context their uses are not prevalent in SMEs. We can propose several explanations. The more common is the high capital investment (material, software, human) which is required to set up a VM system. The second explanation deals with the availability of the simulation models: often at each level a new model has to be built even if it has already done before. The third explanation is linked to the VM dependance on the supporting IT technologies: the compatibility of its software and hardware is essential for its effectiveness. All the problem dealing with data exchange, capacity and accessibility of networks have to be taken into account. In this case one can add the compatibility between human and computer (human- 
machine interface).

Taking these drawbacks as a starting point, several hot topics can be proposed in the VM research area.

-Integration of simulation systems in planning and design tools: Any kind of planning activity can be supported and improved by simulation. The goal to be reached is to implement simulation systems into planning and design tools so that the planner can obtain the benefits from the simulation with a minimum of extra effort.

-Automatic generation of simulation models: Usually, CAD data has to be manipulated to use it for simulation models. The aim is to automatically create ready-to-run simulation models out of CAD data with additional information. Adaptation of a model to specific needs instead of building a totally new one.

-Distributed simulation, optimisation and control: In IT research, multi-agent systems get more and more used. This technology can also be applied to represent distributed systems with autonomous decision making, like it is in a shop floor. In combination with simulation, multi-agent systems can be used for distributed problem solving and optimisation. MAS allows the integration of all simulation tools to achieve virtual manufacture of components.

-Hybrid simulation: A very hot topic is the combination of real and simulated hardware in machine tool and manufacturing system development. Real devices, like the machine controller, would be linked to a simulated model of the machine to test the machine's behaviour during manufacturing.

-Human-computer interfaces:Users expect to interact with the computer in a human like manner. We have to develop good interfaces not only graphical but also mixtures of text, voice, visual, ...

-Virtual prototyping: The aim is to come to reliable and very precise simulation models, which are able to show nearly realistic behaviour under static and dynamic stress. The task is to combine results of different kinds of simulation to predict a nearly realistic behaviour of machine tool, tool and work piece during machining.

\section{CONCLUSION}

As a conclusion of this paper, we can say that we have now reached a point where everyone can use VM. It appears that VM will stimulate the need to design both for manufacturability and manufacturing efficiency. Nowadays, even if there is still a lot of work to do, all the pieces are in place for Virtual Manufacturing to become a standard tool for the design to manufacturing process: (i) computer technology is widely used and accepted, (ii) the concept of virtual prototyping is widely accepted, (iii) companies need faster solutions for cost / time saving, for more accurate simulations, and (iv) leading companies are already demonstrating the successful use of virtual manufacturing techniques.

\section{ACKNOWLEDGMENT}

This work has been done thanks to the EC under framework 5 "Thematic network on Manufacturing Technologies" (MANTYS), carried out under the "competitive and sustainable growth" programme (contract ref. G1RT-CT- 20001-05032) [17.

\section{References}

[1] Ka Iwata and Ma Onosato and $\mathrm{Ka}$ Teramoto and $\mathrm{Sa} \mathrm{A}$. Osaki, "Modeling and Simulation Architecture for Virtual Manufacturing System", Annals CIRP, 44,pp. 399-402, 1995.

[2] Da E. Lee and Ha T. Hahn, "Generic Modular Operations for Virtual Manufacturing Process", Proceedings of DETC'97,ASME Design EngineeringTechnical Conferences, 1997.

[3] Aa Bowyer and Bayliss and Ra Taylor and Pa Willis, "A virtual factory", International Journal of Shape Modeling, Vol. 2 (4), pp. 215-226, 1996.

[4] Ka Kosanke and Fa Vernadat and Ma Zelm", "CIMOSA: enterprise engineering and integration", Computers in Industry, Vol. 40 (2-3), pp. 83-97, 1999.

[5] Edward Lin and Ioannis Minis and Dana S. Nau and William C. Regli, "The institute for System Research, CIM Lab", See also URL www . is . umd. edu/Labs / CIM/vm/vmproject . htm", March, 1997.

[6] Sue Va Ga Cobb and Mirabelle Da D'Cruz and John Ro Wilson ", "Integrated Manufacture: A role for virtual reality?", Int. jour. of Industrial Ergonomics, Vol. 16, pp. 411425, 1995.

[7] Edward Lin and Ioannis Minis and Dana S. Nau and William C. Regli, "Virtual Manufacturing User Workshop", Lawrence Associates Inc., 1994, 12-13 July.

[8] Ma Saadoun and Va Sandoval, "Virtual Manufacturing and its implication", Virtual reality and Prototyping, Laval, France, 1999.

[9] Val Marinov, "What Virtual Manufacturing is? Part I: Definition", See also URL bosphorus.eng.emu.edu.tr/vmarinov/VM/VMdef.htm, October, 2000.

[10] Val Marinov, "What Virtual Manufacturing is? Part II: The Space of Virtual Manufacturing", See also URL bosphorus.eng.emu.edu.tr/vmarinov/VM/VMspace.htm, October, 2000.

[11] Philippe Dépincé and Kristen Tracht and Damien Chablat and Peer Oliver Woelk, "Technical Workshop on Virtual Manufacturing", Future Trends of the Machine Tool Industry, EMO'2003, 2003, October.

[12] Ol Felix Offodile and Layek La Abdel-Malek, "The virtual manufacturing paradigm: The impact of IT/IS outsourcing 
on manufacturing strategy", International Journal of Production Economics, N. 75, pp. 147-159, 2002.

[13] Jo Po To Mo and Mo Zhou, "Tools and methods for managing intangible assets of virtual enterprise", Computers in Industry, N. 51, pp. 197-210, 2003.

[14] Ma Ta Martinez and Pi Fouletier and Ka Ha Park and Ja Favrel, "Virtual Enterprise - organization, evolution and control", International Journal of Production Economics, N. 74, pp. 225-238, 2001.

[15] Anantaram Balakrishnan and Soundar R. T. Kumara and Shankar Sundaresan, "Manufacturing in the digital age: Exploiting Information Technologies for Product Realization", Information Systems Frontiers", Vol. 1 (1), pp. 2550, 1999.

[16] Patrick Chedmail and Damien Chablat and Christophe LeRoy, "A distributed Approach for Access and Visibility Task with a Manikin and a robot in a Virtual Reality Environment", IEEE Transactions on Industrial Electronics, August, 2003.

[17] Philippe Dépincé and Mickael Zwick, "Virtual Manufacturing Trend Report Version 3", CECIMO (MANTYS), 2003, See also URL www . cecimo . be". 